\title{
Enzyme switch by complementary polymer pair system (CPPS)
}

\author{
Shunsuke Tomita, ${ }^{a}$ Len Ito, ${ }^{b, c}$ Hiroshi Yamaguchi, ${ }^{c}$ Gen-ichi Konishi, ${ }^{d}$ Yukio Nagasaki, ${ }^{a, e, f, g, h}$ and Kentaro \\ Shiraki*a,e
}

\author{
${ }_{5}$ Received (in $\left.X X X, X X X\right)$ Xth $X X X X X X X X X 200 X$, Accepted Xth $X X X X X X X X X 200 X$ \\ First published on the web Xth $X X X X X X X X X 200 X$ \\ DOI: 10.1039/b000000x
}

Manipulation of enzyme activity at will presents various research and industrial applications.
Herein we describe development of a technology for inactivation and reactivation of enzyme
activities using a polyanionic poly(acrylic acid) (PAAc) and a polycationic poly(allylamine) (PAA).
Enzyme activities of ribonuclease A (RNase A), lysozyme, cellulase, and $\alpha$-amylase were lost
through addition of PAAc or PAA because of their binding to the enzymes. The activity of these
enzymes except for $\alpha$-amylase was then fully restored from the complex by the addition of
oppositely charged polymers. Such manipulation of enzyme activity using a complementary
polymer pair system (CPPS) enables the expansion of biomedical and biotechnological
applications of the enzymes, including realization of protein delivery and intelligent bioreactors.

\section{Introduction}

Enzymes are invaluable tools for biochemical studies. They also offer important industrial applications in pharmaceutical 20 and biotechnological fields. The utility of enzymes would increase dramatically if we were able to manipulate their activity and stability at will. Several attempts have been made, such as a metal-dependent switch for regulating enzymatic activity: metal binding sites was introduced into the substrate 25 binding pocket of staphylococcal nuclease, thus addition of heavy metal salts inhibited the enzyme activity and subsequently reactivated by chelating agents. ${ }^{1}$ Likewise, temperature-responsive and photo-responsive polymers have been introduced adjacent to the substrate binding cleft of 30 endoglucanase 12A, whose activity was then manipulated by changes in temperature or light conditions. ${ }^{2,3}$ However, these technologies require introduction of a metal binding site or polymers into the enzymes. Manipulation of enzyme activities simply by changing the solvent is expected to present the 35 advantage that the technology would be applicable to any protein without chemical modification. Some examples are the reversible micellization of enzymes with a block copolymer attained by changing the ionic strength, and a pulse electric field used to manipulate the enzyme activity of lysozyme. ${ }^{4,5}$

${ }_{40}$ Nanoparticle surface represents another way to control enzyme activity. Gold nanoparticles with a charged periphery were used to bind an enzyme reversibly and thereby control its activity. ${ }^{6-10}$ Similarly, reversible binding to an enzyme and altering the substrate selectivity were performed using a ${ }_{45}$ charged micelle surface. ${ }^{11}$ It is of interest, that a synthetic polymer from comonomer units tailored for amino acid residues surrounding the active site has been used to manipulate enzyme activity: e.g., lysozyme has been turned off and on again by addition of a synthetic polymeric inhibitor, 50 followed by a superior complexing agent, i.e., polyarginine. ${ }^{12}$

To our knowledge, protein interacts strongly with complementary charged polymer through Coulomb attraction. ${ }^{13-19}$ These interacts result in the formation of various types of charged polymer-protein complexes which 55 have been applied for protein delivery, ${ }^{20-22}$ protein separations, ${ }^{23-25}$ and biosensor. ${ }^{26-28}$ Such a complexation is also relevant to enzyme functions. For example, negatively charged amphiphilic polymers poly(isobutylene-alt-maleic acid) and poly(1-tetradecene-alt-maleic acid) bound positively 60 charged lysozyme, which result in a loss of tertiary structure and enzymatic activity; after that the complex dissociates by the addition of $\mathrm{NaCl}$ or guanidine hydrochloride. ${ }^{29}$ On the basis of the recent development of complexation between protein and charged polymer, we have recently demonstrated 65 a smart polymer, poly(N,N-diethylaminoethyl methacrylate)graft-poly(ethylene glycol), to control enzymatic activity of lysozyme. ${ }^{30}$ As described here, we have developed a versatile method - the complementary polymer pair system (CPPS) - to manipulate a wide type of enzyme activity at will using 70 oppositely charged polymers pair (Fig. 1a). We investigated CPPS with two basic enzymes and two acidic enzymes (Fig. 1b). A charged polymer inactivates enzymes, whereas the oppositely charged polymer reactivated the enzyme (Fig. 1c). The alternative addition of charged polymers during 75 enzymatic reaction successfully demonstrated the reversible switching of enzyme activity.

\section{Experimental}

\section{Materials}

Bovine ribonuclease A (RNase A), hen egg white lysozyme, 80 the Aspergillus niger cellulase, cytidine 2',3'-cyclic monophosphate sodium salt (cCMP), 4-nitrophenyl $\beta$-Dcellobioside (pNPC), 3,5-dinitrosalicylic acid, and 3-( $N$ morpholino)propanesulfonic acid (Mops) were from Sigma Chemical. Co. (St. Louis, USA). The Aspergillus oryzae $\alpha$ 85 amylase and starch indicator solution used for this study were from Fluka Chemica GmbH (Buchs, Switzerland). Sodium hydrogen carbonate, potassium sodium tartrate tetrahydrate, phenol, Micrococcus luteus, poly(acrylic acid) of the average molecular weight of 5000 (PAAc), propionic acid (ProAc), 90 and propylamine chloride (ProAm) were from Wako Pure Chemical Inds., Ltd. (Osaka, Japan). Poly(allylamine) of the average molecular weight of 5000 (PAA) was acquired from Nitto Boseki Co., Ltd. (Fukushima, Japan). All chemicals used were of high-quality analytical grade and were used as 95 received.

\section{Protein concentration}


The respective concentrations of proteins were determined by absorbance at $280 \mathrm{~nm}$ using a spectrophotometer (V-630; Jasco Corp., Tokyo, Japan), with extinction coefficients of 9,440 $\mathrm{M}^{-1} \mathrm{~cm}^{-1}$ (RNase A), 37,970 $\mathrm{M}^{-1} \mathrm{~cm}^{-1}$ (lysozyme), 68,995 ${ }_{5} \mathrm{M}^{-1} \mathrm{~cm}^{-1}$ (cellulase), or $106,160 \mathrm{M}^{-1} \mathrm{~cm}^{-1}$ ( $\alpha$-amylase). ${ }^{31}$

\section{Enzyme assay}

(a) RNase A. A substrate solution of $1.125 \mathrm{ml}$ containing $0.085 \mathrm{mg} \mathrm{ml}^{-1} \mathrm{cCMP}$ and $10 \mathrm{mM}$ Mops buffer ( $\mathrm{pH} 7.0$ ) was 10 mixed with $0.375 \mathrm{ml}$ enzyme solution. The residual activity was estimated from the slope of the initial increase in the absorbance intensity at $284 \mathrm{~nm}$. (b) lysozyme. A substrate solution of $1.125 \mathrm{ml}$ containing $0.32 \mathrm{mg} \mathrm{ml}^{-1} M$. luteus solution and $10 \mathrm{mM}$ Mops buffer ( $\mathrm{pH}$ 7.0) was mixed with

$150.375 \mathrm{ml}$ enzyme solution. The decrease in the light-scattering intensity of the solution was monitored by absorbance at 600 $\mathrm{nm}$. The activity was estimated from the slope of the initial decrease in the intensity. (c) cellulase. A substrate solution of $150 \mu \mathrm{l}$ containing $0.15 \mathrm{mg} \mathrm{ml}^{-1} \mathrm{pNPC}$ and $10 \mathrm{mM}$ Mops 20 buffer ( $\mathrm{pH} 7.0$ ) was mixed with $50 \mu \mathrm{l}$ enzyme solution, and incubated at $50^{\circ} \mathrm{C}$ for $75 \mathrm{~min}$. The reaction was then stopped by boiling for $5 \mathrm{~min}$. The activity was estimated from the absorbance intensity at $410 \mathrm{~nm}$. (d) $\alpha$-amylase. A substrate solution of $495 \mu \mathrm{l}$ containing $1.0 \%$ starch and $10 \mathrm{mM}$ Mops

25 buffer (pH 7.0) was mixed with $5 \mu$ l enzyme solution, and incubated at $37^{\circ} \mathrm{C}$ for $15 \mathrm{~min}$. The reaction was then stopped by boiling for $5 \mathrm{~min}$. The reduction of sugar released from starch was measured as the number of glucose equivalent using the 3,5-dinitrosalicylic acid (DNS) method as described 30 previously. ${ }^{32}$

\section{Circular dichroism}

Circular dichroism (CD) experiments were done in an $1 \mathrm{~cm}$ path-length quartz cuvette using a spectropolarimeter (J-720 ${ }_{35} \mathrm{~W}$; Jasco Corp.). Enzyme solution containing $2.0 \mu \mathrm{M}$ enzymes and $10 \mathrm{mM}$ Mops buffer ( $\mathrm{pH}$ 7.0) was incubated with polymer solution $(0.9 \mu \mathrm{M}$ PAAc for RNase A, $0.9 \mu \mathrm{M}$ PAAc for lysozyme, $0.8 \mu \mathrm{M}$ PAA for cellulase, or $1.5 \mu \mathrm{M}$ PAA for $\alpha$ amylase) at $25^{\circ} \mathrm{C}$ for $2 \mathrm{~h}$ or $12 \mathrm{~h}$. After the CD measurement, 40 the oppositely charged polymer $(0.8 \mu \mathrm{M}$ PAA for RNase A, $0.8 \mu \mathrm{M}$ PAA for lysozyme, $1.5 \mu \mathrm{M}$ PAAc for cellulase, 3.0 $\mu \mathrm{M}$ PAAc for $\alpha$-amylase) were added to the enzyme-polymer solutions. After incubation at $25^{\circ} \mathrm{C}$ for $2 \mathrm{~h}$, the aggregates of PAAc-PAA complex were removed by centrifugation at $4515,000 \times g$ for $20 \mathrm{~min}$ at $25^{\circ} \mathrm{C}$ and the spectrum was measured at $25^{\circ} \mathrm{C}$. The $\mathrm{CD}$ spectra of the samples were corrected by subtracting the corresponding spectra of buffers in the absence of enzymes.

\section{${ }_{50}$ Inactivation and reactivation of RNase A}

Various concentrations of PAAc, PAA, and ProAc were added to solutions containing $2.0 \mu \mathrm{M}$ RNase A and $10 \mathrm{mM}$ Mops buffer ( $\mathrm{pH}$ 7.0). After incubation at $25^{\circ} \mathrm{C}$ for $2 \mathrm{~h}$, the residual activity was measured. Reactivation of RNase A was 55 performed by adding PAA and ProAm to RNase A-PAAc complex solution. Various concentrations of PAA and ProAm were added to solutions containing $2.0 \mu \mathrm{M}$ RNase A, $0.9 \mu \mathrm{M}$ PAAc, and $10 \mathrm{mM}$ Mops buffer ( $\mathrm{pH}$ 7.0). After incubation at $25^{\circ} \mathrm{C}$ for $2 \mathrm{~h}$, the samples were centrifuged at $15000 \times g$ for $6020 \mathrm{~min}$ at $25^{\circ} \mathrm{C}$. Then the residual activity was measured.

Direct measurement of RNase A activity switching was performed by adding PAAc and PAA solutions to a running enzyme reaction solution alternating order in a $2 \mathrm{~mm}$ pathlength quartz cuvette at $25^{\circ} \mathrm{C}$. RNase A assay ( $750 \mu \mathrm{l}$ solution 65 containing $0.2 \mu \mathrm{M}$ RNase A, $0.4 \mathrm{mg} \mathrm{ml}^{-1}$ cCMP, and $10 \mathrm{mM}$ Mops ( $\mathrm{pH}$ 7.0)) was stopped by addition of a $10 \mu \mathrm{M}$ PAAc solution (3.4 $\mu \mathrm{l}, 0.23$ equiv). After that, a $10 \mu \mathrm{M}$ PAA solution (3.0 $\mu \mathrm{l}, 0.20$ equiv) was injected and restored enzyme activity. Finally, the enzyme reaction was again led to an 70 arrest by addition of a $10 \mu \mathrm{M}$ PAAc solution $(4.4 \mu \mathrm{l}, 0.30$ equiv).

\section{Inactivation and reactivation of lysozyme}

Various concentrations of PAAc, PAA, and ProAc were added 75 to solutions containing $2.0 \mu \mathrm{M}$ lysozyme and $10 \mathrm{mM}$ Mops buffer ( $\mathrm{pH} 7.0$ ). After incubation at $25^{\circ} \mathrm{C}$ for $2 \mathrm{~h}$, the residual activity was measured. Reactivation of lysozyme was performed by adding PAA and ProAm to lysozyme-PAAc complex solution. Various concentrations of PAA and ProAm 80 was added to solutions containing $2.0 \mu \mathrm{M}$ lysozyme, $0.9 \mu \mathrm{M}$ PAAc, and $10 \mathrm{mM}$ Mops buffer ( $\mathrm{pH}$ 7.0). After incubation at $25^{\circ} \mathrm{C}$ for $2 \mathrm{~h}$, the samples were centrifuged at $15000 \times g$ for $20 \mathrm{~min}$ at $25^{\circ} \mathrm{C}$. Then the residual activity was measured.

Direct measurement of lysozyme activity switching was 85 performed by adding PAAc and PAA solutions to a running enzyme reaction solution alternating order in an $1 \mathrm{~cm}$ pathlength quartz cuvette at $25^{\circ} \mathrm{C}$. Lysozyme assay ( $2 \mathrm{ml}$ solution containing $0.08 \mu \mathrm{M}$ lysozyme, $0.24 \mathrm{mg} \mathrm{ml}^{-1} \mathrm{M}$. luteus, and 10 mM Mops ( $\mathrm{pH} 7.0$ )) was stopped by addition of a $50 \mu \mathrm{M}$ 90 PAAc solution ( $3.0 \mu \mathrm{l}, 0.94$ equiv). After that, a $50 \mu \mathrm{M}$ PAA solution ( $6.0 \mu \mathrm{l}, 1.88$ equiv) was injected and restored enzyme activity. Finally, the enzyme reaction was again led to an arrest by addition of a $50 \mu \mathrm{M}$ PAAc solution $(7.0 \mu \mathrm{l}, 2.19$ equiv).

\section{Inactivation and reactivation of cellulase}

Various concentrations of PAA, PAAc, and ProAm were added to solutions containing $2.0 \mu \mathrm{M}$ cellulase and $10 \mathrm{mM}$ Mops buffer ( $\mathrm{pH} 7.0)$. After incubation at $25^{\circ} \mathrm{C}$ for $2 \mathrm{~h}$, the 100 residual activity was measured. Reactivation of cellulase was performed by adding PAAc and ProAc to cellulase-PAA complex solution. Various concentrations of PAAc and ProAc was added to solutions containing $2.0 \mu \mathrm{M}$ cellulase, $0.8 \mu \mathrm{M}$ PAA, and $10 \mathrm{mM}$ Mops buffer ( $\mathrm{pH}$ 7.0). After incubation at $10525^{\circ} \mathrm{C}$ for $2 \mathrm{~h}$, the samples were centrifuged at $15000 \times g$ for $20 \mathrm{~min}$ at $25^{\circ} \mathrm{C}$. The residual activity was measured.

Direct measurement of cellulase activity switching was performed by adding PAA and PAAc solutions to a running enzyme reaction solution alternating order in an $1 \mathrm{~cm}$ path110 length quartz cuvette at $50{ }^{\circ} \mathrm{C}$. Cellulase assay (solution of 2.5 $\mathrm{ml}$ containing $0.5 \mu \mathrm{M}$ cellulase, $0.2 \mathrm{mg} \mathrm{ml}^{-1}$ pNPC, and 10 mM Mops ( $\mathrm{pH}$ 7.0)) was stopped by addition of a $50 \mu \mathrm{M}$ PAA solution (7.5 $\mu \mathrm{l}, 0.30$ equiv). After that, a $50 \mu \mathrm{M}$ PAAc solution (12.5 $\mu \mathrm{l}, 0.50$ equiv) was injected and restored 115 enzyme activity. Finally, the enzyme reaction was again led to an arrest by addition of a $50 \mu \mathrm{M}$ PAA solution (10.0 $\mu \mathrm{l}, 0.40$ equiv). The switching data was obtained by background subtraction.

\section{Inactivation and reactivation of $\boldsymbol{\alpha}$-amylase}

Various concentrations of PAA, PAAc, and ProAm were added to solutions containing $2.0 \mu \mathrm{M} \alpha$-amylase and $10 \mathrm{mM}$ 
Mops buffer ( $\mathrm{pH} 7.0$ ). After incubation at $25^{\circ} \mathrm{C}$ for various periods, the residual activity was measured. Reactivation of $\alpha$-amylase was performed by adding PAAc and ProAc to $\alpha$ amylase-PAA complex solution. Various concentrations of ${ }_{5}$ PAAc and ProAc was added to solutions containing $2.0 \mu \mathrm{M}$ $\alpha$-amylase, $1.5 \mu \mathrm{M}$ PAA, and $10 \mathrm{mM}$ Mops buffer (pH 7.0). After incubation at $25^{\circ} \mathrm{C}$ for 2 or $12 \mathrm{~h}$, the samples were centrifuged at $15000 \times \mathrm{g}$ for $20 \mathrm{~min}$ at $25^{\circ} \mathrm{C}$. Then the residual activity was measured.

\section{Result and Discussion}

\section{CPPS for RNase A}

We have investigated CPPS for positively charged RNase A as a first model. Fig. 2a presents the enzyme activity of RNase $15 \mathrm{~A}$ when $2.0 \mu \mathrm{M}$ of the enzyme was mixed with PAAc. The enzyme activity decreased concomitantly with the PAAc concentration; the mid-point concentration $\left(\mathrm{IC}_{50}\right)$ was 0.21 $\mu \mathrm{M}$. Assuming that binding of the enzyme to the polymer is involved in activity loss, the results imply that $0.21 \mu \mathrm{M}$ of the 20 PAAc bound $1.0 \mu \mathrm{M}$ of the enzyme. Consequently, the polymer binds about 5 mol RNase A per mole of polymer. The enzyme activity completely disappeared at about $0.5 \mu \mathrm{M}$ PAAc. It is predicted because net charge of PAAc is very high compared with that of the enzymes, i.e., $60 \%$ of PAAc units 25 were charged at $\mathrm{pH}$ of 7.0 ; PAAc has a total of about 40 negative charges, ${ }^{33}$ although RNase $\mathrm{A}$ has a net positive charge of 4 at the experimental $\mathrm{pH}$ of 7.0. Therefore, the substoichiometric salt bonds were likely to form between PAAc and RNase A.

30 During and after this titration, no precipitation was observed, indicating that RNase A-PAAc complex is soluble. As described above, the PAAc appears to bind five RNase A molecules when RNase A is in excess. However, as the PAAc concentration is increased, it is expected that RNase A 35 molecules distribute to the polymers, engendering different complexes of 5:1 to $0: 1$ of RNase A:PAAc. Consequently, the complex formation engenders the excess net charges, irrespective of having a 5:1 to 1:1 ratio. These excess negative charges might be sufficient for complex solubility. The ${ }_{40}$ observed loss of RNase A activity is attributable to the complex formation, which interfered with substrate binding. Alternatively, the PAAc bound directly to the active center of the enzyme, which has a cluster of positive charges (see Fig. $1 b)$.

45 The enzyme activity of RNase A was fully maintained in the presence of PAA or ProAc (even at the highest concentration $200 \mu \mathrm{M}$ for ProAc) (see Fig. S1a, ESI $\dagger$ ). No effect of PAA is expected because the cationic nature of this polymer probably has no affinity for the cationic RNase A. ${ }_{50}$ The lack of an effect of ProAc is likely to be attributable to its monovalency, which does not provide sufficient binding affinity for RNase A and suggests in turn that the polyanionic property of PAAc is necessary for the observed stoichiometric binding of this polymer to the protein.

55 The addition of positively charged PAA to RNase A-PAAc complex formed (2.0 $\mu \mathrm{M}$ RNase A and $0.9 \mu \mathrm{M}$ PAAc) caused concentration-dependent recovery of enzyme activity (Fig. 2b). There was no detectable recovery less than 0.2 equiv of PAA (for PAAc), indicating that PAA interacted with free PAAc,

60 but the activity increased sharply above this concentration. Therefore, almost all of the $2.0 \mu \mathrm{M}$ enzyme that formed a complex with PAAc, as described above, must be reactivated by the addition of 0.7 equiv of PAA. Assuming that this is accomplished by dissociation of the enzyme from PAAc. The 65 results described above suggest that the PAA appears to bind 1.4 of PAAc molecules, which shows a certain extent of agreement with the number of positive charges of PAA; $80 \%$ of PAA units were charged at $\mathrm{pH}$ of 7.0, thus PAA has about 70 positive charges. ${ }^{33}$ Because of high charge density of 70 polymers, PAAc-PAA interaction may be stronger than RNase A-PAAc interaction, which leading to the formation of more stable PAA-PAAc complexes and hence PAAc is detached from the complexes with RNase A, in analogy with synthetic polycation and polyanion with $\mathrm{DNA},{ }^{34}$ another synthetic 75 polyanion, ${ }^{35}$ and anionic liposome ${ }^{36}$ system. The observed recovery is attributable to the complex between PAAc and PAA. Therefore, it is possible to manipulate enzyme activity simply by adding oppositely charged polymers. The addition of PAAc switches off the RNase A activity. The lost activity 80 is switched back on by the addition of PAA.

The observed loss of enzyme activity by the bound PAAc might be the result of conformational changes of the enzyme. ${ }^{6,7,29}$ This possibility was also tested using CD spectroscopy (see Fig. S3, ESI $\dagger$ ). The far-UV CD spectrum of 85 inactivated RNase A was insignificantly changed, and the CD feature became essentially same when the enzyme was recovered by PAA, indicating that the secondary structure of RNase A was retained after inactivation and recovery by polymers. Consequently, it is evident that the observed 90 activity loss of RNase A is the binding of PAAc and that it is attributable to the inhibition of the substrate binding and/or a catalytic function.

On the basis of the result shown in Fig. 2a and 2b, a switching of RNase A reaction by the alternate addition of ${ }_{95}$ PAAc and PAA was expected. Indeed, Fig. 2c shows such a successive switching monitored by the hydrolysis of the substrate cCMP as followed by UV spectroscopy; the addition of 0.23 equiv of PAAc caused $90 \%$ inhibition of the product (3'-cytidine monophosphate) release. Subsequently, 0.20 100 equiv of PAA were added to this solution, and the enzyme activity gained with $93 \%$ of its original efficiency. Finally, 0.3 equiv of PAAc were injected and the enzyme ceased to work (8\%). Thus, the on-off regulation of the RNase A activity can be repeated by a simple external addition of 105 polymers. This result suggests that the formation of RNase APAAc complex and PAAc-PAA complex proceeded immediately.

\section{CPPS for lysozyme}

110 A similar effect of PAAc might be expected for lysozyme that is also positively charged at $\mathrm{pH}$ 7.0. Fig. 3a presents data of titration of $2.0 \mu \mathrm{M}$ lysozyme by PAAc. PAAc solely prohibited the lysozyme activity similar to the data of RNase A; there was no precipitation and the $\mathrm{IC}_{50}$ value was $0.19 \mu \mathrm{M}$, 115 indicating that multiple electrostatic interactions are required for the inhibition. The enzyme activity of lysozyme was nonexistent in the presence of $0.7 \mu \mathrm{M}$ PAAc. Although the net charge of lysozyme at $\mathrm{pH} 7.0$ is twice as many as that of RNase A, the PAAc concentration required for binding is 120 nearly identical to the stoichiometric amount required for RNase A. For example, PAAc showed 50\% inhibition at 0.19 $\mu \mathrm{M}$, about 5 lysozyme bound to one PAAc, indicating that binding of PAAc to lysozyme is much stronger than the binding of PAAc to RNase A. This is expected from the fact 125 that lysozyme has a homogeneous distribution of charges. 
Fully inactivated lysozyme in the presence of PAAc was titrated by the addition of PAA. As depicted in Fig. 3b, the concentration dependence of activity recovery was observed, reaching up to $100 \%$ at about 1.0 equiv of PAA (for PAAc). 5 These data indicate that lysozyme activity can also be manipulated using two oppositely charged polymers.

The far-UV CD spectra of lysozyme were little increased in the presence of PAAc, and completely reverted after the addition of PAA (see Fig. S3, ESI $\dagger$ ). The structure of 10 lysozyme is little changed by inactivation and recovery processes.

The on-off control of lysozyme reaction responding to the addition of PAAc and PAA were demonstrated by monitoring from a decrease in the absorbance at $600 \mathrm{~nm}$ due to the 15 rupture of the M. luteus cell wall (Fig. 3c). By addition of 0.94 equiv of PAAc, we observed gradual decreasing of the enzyme activity, reaching $9 \%$ of its original efficiency, indicating that the formation of lysozyme-PAAc complex rate was relatively slow. The hydrolytic activity of lysozyme was 20 then immediately recovered by the addition of 1.88 equiv of PAA. Finally, the enzyme reaction of lysozyme was again shut-off by the addition of 2.19 equiv of PAAc.

\section{CPPS for cellulase}

25 It was anticipated that enzyme switching was demonstrated the reverse combination, i.e., anionic enzyme and cationic polymer. Therefore, we examined CPPS on cellulase that is negatively charged. The addition of PAA caused the formation of dispersible aggregates composed of cellulase30 PAAc complexes and concentration-dependent inactivation of cellulase with a complete reduction of the activity at $0.5 \mu \mathrm{M}$ PAA, although the activity was not influenced by the presence of PAAc or ProAm (Fig. 4a and S1, ESI†). The interaction is nearly stoichiometric because a quantity as small as $0.5 \mu \mathrm{M}$ is 35 sufficient to inactivate $2.0 \mu \mathrm{M}$ cellulase completely, suggesting about 4 cellulase bound to one PAA. As in RNase A and lysozyme, the polymer can bind multiple enzyme molecules.

Even with formation of aggregates, the addition of PAAc 40 supported recovery of enzyme activity, suggesting that PAAc binds to PAA and releases cellulase trapped in the aggregation (Fig. 4b). The addition of 1.5 equiv of PAAc (for PAA) is apparently sufficient to interact with PAA used to inactivate cellulase, which is nearly consistent with the RNase A and 45 lysozyme data that one PAA might be able to bind 1.4 PAAc.

Fig. 4c shows the far-UV CD spectra of cellulase in the processes of inactivation and recovery, clearly indicating structural changes was caused by PAA binding. The secondary structure of cellulase in the presence of PAA is 50 characterized by an unusual negative peak at about $225 \mathrm{~nm}$, completely different from the native structure. The change of CD signal result from the formation of aggregates and changed tertiary structure of cellulase due to the hydrophobic backbone of PAA. ${ }^{37,38}$ Therefore, the binding of a partially 55 hydrophobic PAA to the protein surface will reduce electrostatic repulsion between enzyme molecules and hence make it easier for them to aggregate. The far-UV CD spectra of cellulase were, however, highly recovered after the addition of PAAc, which shows coincidence of the results described 60 above.

We found that cellulase was also able to switch enzymatic activity by external added polymer pairs, which was carried out by monitoring from an increase in the absorbance at 410 nm due to the product ( $p$-nitrophenol) (Fig. 4d). As PAA was 65 added, the solution slightly turns cloudy due to the formation of aggregates. Thus, the correct time-dependence of $p$ nitrophenol produce was determined by subtracting the control experiment data which conducted only using cellulase and polymers without substrate pNPC to that with substrate. 70 The addition of 0.30 equiv of PAA caused $92 \%$ inhibition of the product release. Next, 0.50 equiv of PAAc were added to this solution, and the enzyme started to work again with $97 \%$ of its original efficiency. Subsequent the addition of 0.40 equiv of PAA induced the enzyme inactivation (10 \%). This 75 result suggests that cellulase-PAA complex forms quickly as well as RNase A.

\section{CPPS for $\alpha$-amylase}

We further investigated CPPS on negatively charged $\alpha$ 80 amylase. Fig. 5a portrays the activity change of $2.0 \mu \mathrm{M} \alpha$ amylase as a function of PAA. The addition of PAA caused the formation of a dispersible aggregation and concentrationdependent inactivation of the enzyme with an $85 \%$ reduction of the activity at $1.5 \mu \mathrm{M}$ PAA. Differ from three enzymes, the 85 enzyme activity of $\alpha$-amylase in the presence of PAA decreased with incubation time (Fig. 5b). Consequently, it appears that the binding of PAAc is followed by a slow reaction that causes further activity loss.

The complex between $2.0 \mu \mathrm{M} \alpha$-amylase and $1.5 \mu \mathrm{M}$ PAA 90 incubated for $2 \mathrm{~h}$ was titrated with PAAc, resulting in fully recovery of the activity (Fig. 5c). The activity recovery was less when the complex was incubated longer (12 h), consistent with the observed slow inactivation of the enzyme with PAAc. Fig. 5d shows the far-UV CD spectra of $\alpha$-amylase in the 95 processes of inactivation and recovery. The CD spectrum was completely disappeared in the presence of PAA, clearly indicating structural changes by PAA binding. The far-UV CD spectrum of $\alpha$-amylase with short incubation was, however, highly recovered after the addition of PAAc, while it was 100 partially recovered for long incubation, which shows coincidence of the results described above. The lower activity recovery for $\alpha$-amylase is most likely the result of the irreversible unfolding of $\alpha$-amylase. The binding of PAA to $\alpha$-amylase might have caused multiple contacts between the 105 polymer and the protein, leading to irreversible unfolding of the protein. ${ }^{6}$ This unfolding indicates that weakening the binding strength or aggregability improves the reversibility of activity loss, even for less stable proteins.

\section{${ }_{110}$ Conclusions}

This paper presents complementary polymer pair system (CPPS) that is useful to manipulate enzyme activity reversibly. Negatively or positively charged polymers bind to the proteins by electrostatic interactions, engendering a loss of activity. 115 The activity loss is attributable to binding of the polymer and blocking of the active site. Binding of the PAAc to RNase A and lysozyme caused no conformational changes, while the complex of PAA with cellulase and $\alpha$-amylase underwent the formation of aggregates and changed tertiary structure. ${ }_{120}$ Complex formation of RNase A, lysozyme, and cellulase was completely reversible, as expected from the high stability of these proteins. In contrast, the activity of $\alpha$-amylase was mostly lost upon binding to the polymer, which might be attributable to its multiple domains. 
The advantages of CPPS can be summarized as follows: (i) CPPS controls enzyme activity of any proteins without chemical modifications; (ii) off-polymer that binds to and inactivate the enzyme is separated easily by the complex of 5 on-polymer as a precipitate; (iii) CPPS occurs through noncovalent electrostatic interactions between the protein and polymer. We believe that CPPS will not only be applied to control of biologically or industrially important protein function, but also protein delivery and intelligent bioreactors, 10 because proteins are noncovalently fixed on a carrier or a substrate with inactivated state and then the proteins are easily released by charged polymer when needed.

\section{Acknowledgement}

We are grateful to Dr. T. Arakawa, Alliance Protein 15 Laboratories, for valuable discussion.

\section{References}

1 D. R. Corey and P. G. Schultz, J. Biol. Chem., 1989, 264, 3666-3669.

2 T. Shimoboji, E. Larenas, T. Fowler, S. Kulkarni, A. S. Hoffman and P. S. Stayton, Proc. Natl. Acad. Sci. U. S. A., 2002, 99, 16592-16596.

203 T. Shimoboji, E. Larenas, T. Fowler, A. S. Hoffman and P. S. Stayton, Bioconjug. Chem., 2003, 14, 517-525.

4 A. Harada and K. Kataoka, J. Am. Chem. Soc., 1999, 121, 9241-9242.

5 A. Harada and K. Kataoka, J. Am. Chem. Soc., 2003, 125, 1530615307.

256 N. O. Fischer, A. Verma, C. M. Goodman, J. M. Simard and V. M. Rotello, J. Am. Chem. Soc., 2003, 125, 13387-13391.

7 R. Hong, N. O. Fischer, A. Verma, C. M. Goodman, T. Emrick and V. M. Rotello, J. Am. Chem. Soc., 2004, 126, 739-743.

8 A. Verma, J. M. Simard and V. M. Rotello, Langmuir., 2004, 20 , 4178-4181.

9 A. Verma, J. M. Simard, J. W. Worrall and V. M. Rotello, J. Am. Chem. Soc., 2004, 126, 13987-13991.

10 H. Bayraktar, P. S. Ghosh, V. M. Rotello and M. J. Knapp, Chem. Commun., 2006, , 1390-1392.

3511 B. S. Sandanaraj, D. R. Vutukuri, J. M. Simard, A. Klaikherd, R. Hong, V. M. Rotello and S. Thayumanavan, J. Am. Chem. Soc., 2005, 127, 10693-10698.

12 K. Wenck, S. Koch, C. Renner, W. Sun and T. Schrader, J. Am. Chem. Soc., 2007, 129, 16015-16019.

4013 D. Takahashi, Y. Kubota, K. Kokai, T. Izumi, M. Hirata and E. Kokufuta, Langmuir., 2000, 16, 3133-3140.

14 T. M. Foreman, M. Khalil, P. Meier, J. R. Brainard, L. A. Vanderberg and N. N. Sauer, Biotechnol. Bioeng., 2001, 76, 241-246.

15 E. Seyrek, P. L. Dubin, C. Tribet and E. A. Gamble, Biomacromolecules., 2003, 4, 273-282.

16 C. L. Cooper, P. L. Dubin, A. B. Kayitmazer and S. Turksen, Curr. Opin. Colloid. Interface. Sci., 2005, 10, 52-78.

17 C. L. Cooper, A. Goulding, A. B. Kayitmazer, S. Ulrich, S. Stoll, S. Turksen, S. Yusa, A. Kumar and P. L. Dubin, Biomacromolecules., 2006, 7, 1025-1035.

18 A. Wittemann and M. Ballauff, Phys. Chem. Chem. Phys., 2006, 8, 5269-5275.

19 A. Kawamura, C. Kojima, M. Iijima, A. Harada and K. Kono, J. Polym. Sci. Part. A,. Polymer. Chem., 2008, 46, 3842-3852.

5520 G. B. Sukhorukov and H. Mohwald, Trends. Biotechnol., 2007, 25, 93-98.

21 K. T. Oh, T. K. Bronich, V. A. Kabanov and A. V. Kabanov, Biomacromolecules., 2007, 8, 490-497.

22 Y. Lee, T. Ishii, H. Cabral, H. J. Kim, J. H. Seo, N. Nishiyama, H.

60 Oshima, K. Osada and K. Kataoka, Angew. Chem. Int. Ed. Engl., 2009, 48, 1-5.

23 C. A. Luces, S. O. Fakayode, M. Lowry and I. M. Warner, Electrophoresis., 2008, 29, 889-900.

24 M. Braia, M. C. Porfiri, B. Farruggia, G. Pico and D. Romanini, J.

65 Chromatogr. B. Analyt. Technol. Biomed. Life. Sci., 2008, 873, 139143.

25 V. N. Wong, G. Fernando, A. R. Wagner, J. Zhang, G. R. Kinsel, S. Zauscher and D. J. Dyer, Langumuir., 2009, 25, 1459-1465.

26 L. Liu, F. Zhang, F. Xi and X. Lin, Biosens. Bioelectron., 2008, 24, 306-312.
27 H. T. Zheng, J. L. Zhou, Y. S. Okezaki and S. I. Suye, Electroanalysis., 2008, 20, 2685-2691.

28 F. Lisdat, R. Dronov, H. Mohwald, F. W. Scheller and D. G. Kurth, Chem. Commun., 2009, , 274-283.

7529 G. Gao and P. Yao, J. Polymer. Sci. Polymer. Chem., 2008, 46, 46814690.

30 S. Ganguli, K. Yoshimoto, S. Tomita, H. Sakuma, T. Matsuoka, K. Shiraki and Y. Nagasaki, J. Am. Chem. Soc., 2009, 131, 6549-6553.

31 C. N. Pace, F. Vajdos, L. Fee, G. Grimsley and T. Gray, Protein. Sci., 1995, 4, 2411-2423.

32 S. Aiba, K. Kitai and T. Imanaka, Appl. Environ. Microbiol., 1983, 46, 1059-1065.

33 A. I. Petrov, A. A. Antipov and G. B. Sukhorukov, Macromolecules., 2003, 36, 10079-10086.

8534 V. A. Izumrudov, S. I. Kargov, M. V. Zhiyakova, A. B. Zezin and V. A. Kabanov, Biopolymers., 1995, 35, 523-532.

35 A. V. Kabanov, T. K. Bronich, V. A. Kabanov, K. Yu and A. Eisenberg, Macromolecules., 1996, 29, 6797-6802.

36 D. V. Volodkin, P. Schaaf, H. Mohwald, J. C. Voegel and V. Ball, Soft. Matter., 2009, 5, 1394-1405.

37 S. L. Clark and P. T. Hammond, Langmuir., 2000, 16, 10206-10214.

38 X. P. Jiang, C. Ortiz and P. T. Hammond, Langmuir., 2002, 18, 11311143.

$95{ }^{a}$ Graduate School of Pure and Applied Sciences, University of Tsukuba, 1-1-1 Tennodai, Tsukuba, Ibaraki 305-8573, Japan, E-mail: shiraki@bk.tsukuba.ac.jp; Fax: +81-29-8535215; Tel: +81-29-8535306

${ }^{b}$ Japan Synchrotron Radiation Research Institute, 1-1-1 Kouto, Sayo, Hyogo 679-5198, Japan,

$100{ }^{c}$ School of Science and Technology, Kwansei Gakuin University, 2-1 Gakuen, Sanda, Hyogo 669-1337, Japan,

${ }^{d}$ Department of Organic and Polymeric Materials, Graduate School of Science and Engineering, Tokyo Institute of Technology, 2-12-1-H-134 Ookayama, Meguro-ku, Tokyo 152-8552, Japan,

$105{ }^{e}$ Center for Tsukuba Advanced Research Alliance (TARA), University of Tsukuba, 1-1-1, Tennodai, Tsukuba, Ibaraki 305-8577, Japan,

${ }^{f}$ Tsukuba Research Center for Interdisciplinary Materials Science (TIMS), University of Tsukuba, 1-1-1 Tennodai, Tsukuba, Ibaraki 305-8571, Japan,

$110{ }^{g}$ Graduate School of Comprehensive Human, University of Tsukuba, 1-11 Tennodai, Tsukuba, Ibaraki 305-8571, Japan,

${ }^{h}$ Satellite Laboratory of International Center for Materials Nanoarchitechtonics (MANA), National Institute of Materials Science (NIMS), 1-1-1 Tennodai, Tsukuba, Ibaraki 305-8573, Japan

$115 \dagger$ Electronic supplementary information (ESI) available: Fig.S1 The effect of the identically charged polymers and the monomers of charged polymers on enzyme activity. Fig.S2 The effect of the monomers of charged polymers on recovery of enzyme activity. Fig.S3 CD spectra of RNase A and lysozyme in the processes of inactivation and recovery. See 120 DOI: $10.1039 /$ b000000x

(a)
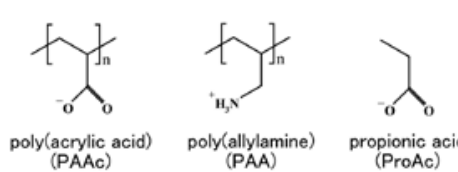

(b)

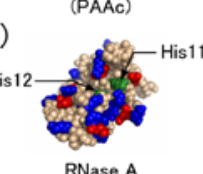

RNase $A$
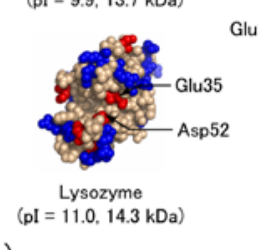

(c)

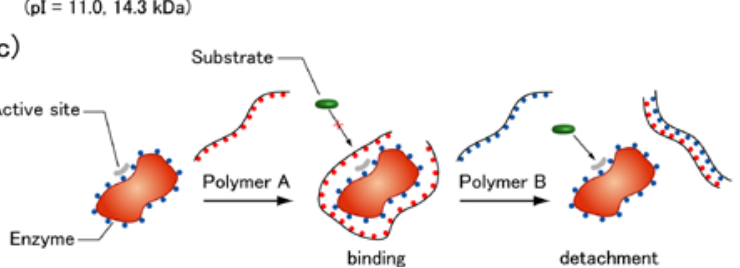


Fig. 1 (a) Chemical structure of compounds used in this study. (b) X-ray crystal structure of four enzymes [PDB entry RNase A, 2AAS; lysozyme, $1 \mathrm{HEL}$; cellulase, $1 \mathrm{KS} 5 ; \alpha$-amylase, 6TAA]. Acidic amino acids including the catalytic residues (lysozyme; Glu 35 and Asp 52, cellulase; Glu 116

5 and Glu 204, $\alpha$-amylase; Asp 206, Glu 230, and Glu 297), red; basic amino acids, blue; the catalytic residues of RNase A (His 12 and His 119); green. (c) Schematic illustration of CPPS.

(a)

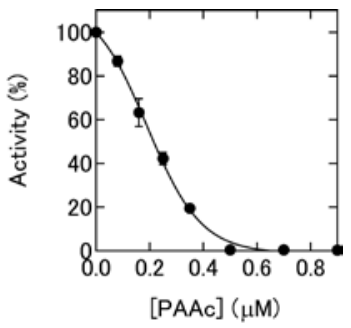

(b)

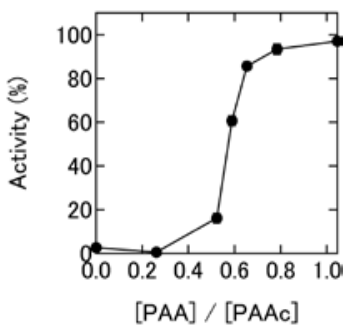

(c)

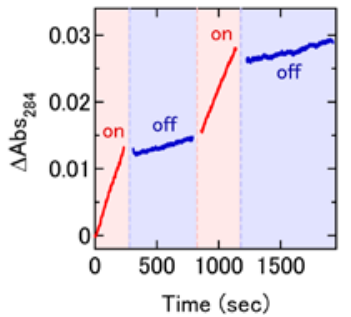

10 Fig. 2 CPPS for RNase A. (a) Inactivation of $2.0 \mu \mathrm{M}$ RNase A activity by PAAc. (b) Recovery of enzyme activity of RNase A by PAA. Various concentrations of PAA were added to solutions containing $2.0 \mu \mathrm{M}$ RNase A and $0.9 \mu$ M PAAc. (c) Sequential switching of the activity of RNase A by the alternate addition of PAAc and PAA.

(a)

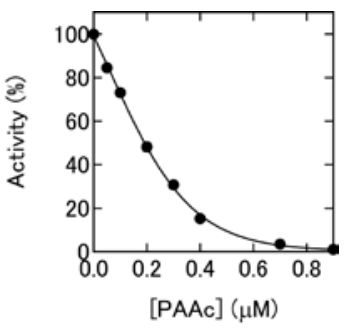

(b)

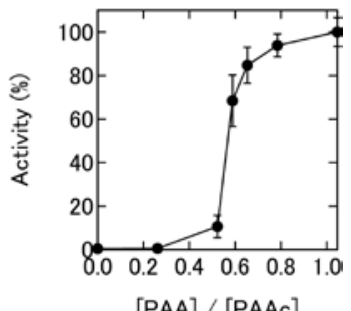

(c)

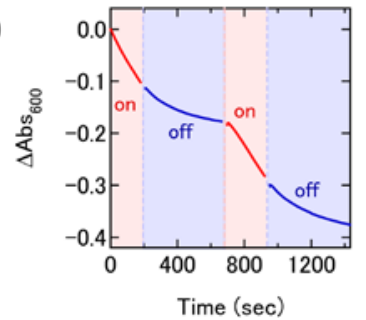

Fig. 3 CPPS for lysozyme. (a) Inactivation of $2.0 \mu \mathrm{M}$ lysozyme activity by PAAc. (b) Recovery of enzyme activity of lysozyme by PAA. Various concentrations of PAA were added to solutions containing $2.0 \mu \mathrm{M}$ lysozyme and $0.9 \mu \mathrm{M}$ PAAc. (c) Sequential switching of the activity of 20 lysozyme by the alternate addition of PAAc and PAA. (a)

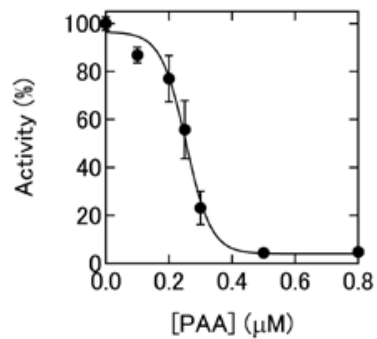

(c)

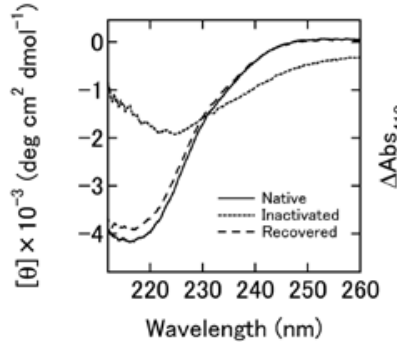

(b)

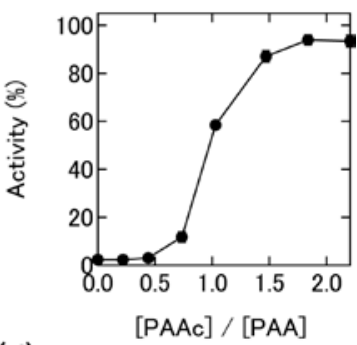

(d)

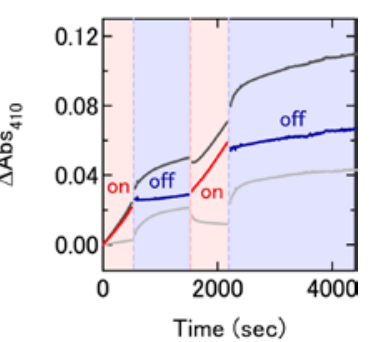

Fig. 4 CPPS for cellulase. (a) Inactivation of $2.0 \mu \mathrm{M}$ cellulase activity by PAA. (b) Recovery of enzyme activity of cellulase by PAAc. Various concentrations of PAAc were added to solutions containing $2.0 \mu \mathrm{M}$ 25 cellulase and $0.8 \mu \mathrm{M}$ PAA. (c) CD spectra of cellulase in the processes of inactivation and recovery. $2.0 \mu \mathrm{M}$ cellulase was inactivated by $0.8 \mu \mathrm{M}$ PAA, and then recovered by $1.5 \mu \mathrm{M}$ PAAc. Native cellulase, solid line; inactivated cellulase, dotted line; recovered cellulase, broken line. (d) Sequential switching of the activity of cellulase by the alternate addition 30 of PAA and PAAc. The correct time-dependence of p-nitrophenol produce was determined by subtracting the titration data without pNPC (light gray) from that with pNPC (dark gray). (a)

(c)
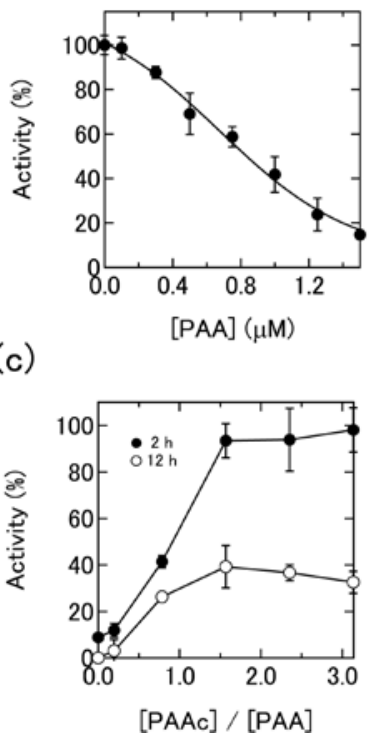

(b)

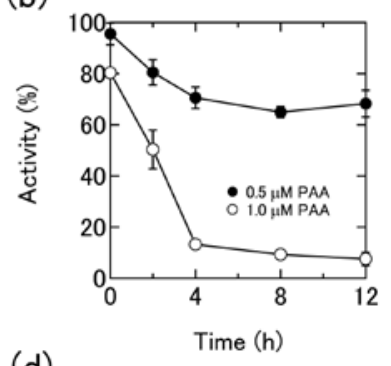

(d)

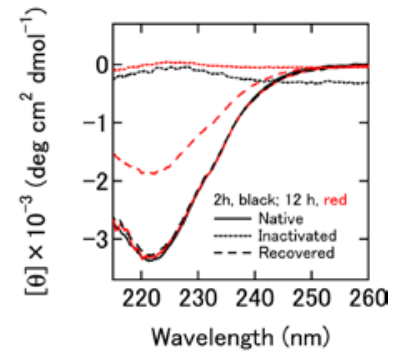

35 Fig. 5 CPPS for $\alpha$-amylase. (a) Inactivation of $2.0 \mu \mathrm{M} \alpha$-amylase activity by PAA. (b) Time course inactivation of $2.0 \mu \mathrm{M} \alpha$-amylase by $0.5 \mu \mathrm{M}$ (closed circles) and $1.0 \mu \mathrm{M}$ (open circles) PAA. (c) Recovery of enzyme activity of $\alpha$-amylase by PAAc. Various concentrations of PAAc were added to solutions containing $2.0 \mu \mathrm{M} \alpha$-amylase and $1.5 \mu \mathrm{M}$ PAA after

40 incubated for $2 \mathrm{~h}$ (closed circles) or $12 \mathrm{~h}$ (open circles). (d) CD spectra of $\alpha$-amylase in the processes of inactivation and recovery. $2.0 \mu \mathrm{M} \alpha$ amylase was inactivated by $1.5 \mu \mathrm{M}$ PAA and incubated for $2 \mathrm{~h}$ (black) or $12 \mathrm{~h}$ (red), and then $\alpha$-amylase were recovered by $3.0 \mu \mathrm{M}$ PAAc. Native 
$\alpha$-amylase, solid line; inactivated $\alpha$-amylase, dotted line; recovered $\alpha$ amylase, broken line. 


\section{A graphical contents entry}

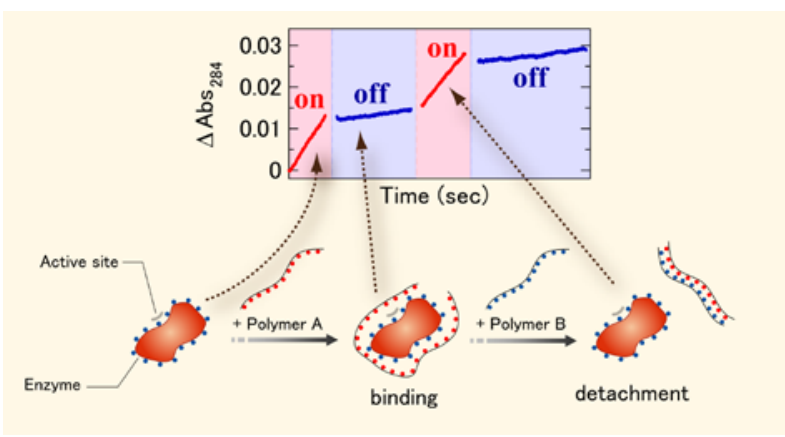

The activity of a wide type of enzymes is manipulated at will using oppositely charged polymers pair (anionic poly(acrylic 5 acid) and cationic poly(allylamine)). 